\title{
ZONEAMENTO DO DISTRITO DE RANCHARIA, MUNICÍPIO DE LIMA DUARTE, MG, ENTORNO DO PARQUE ESTADUAL DA SERRA DO IBITIPOCA, COM FINS DE MANEJO DO ECOTURISMO'
}

Werter Valentim de Moraes², Guido Assunção Ribeiro $^{3}$, Gumercindo Souza Lima ${ }^{3}$ e Wantuelfer Gonçalves ${ }^{3}$

\begin{abstract}
RESUMO - O objetivo deste trabalho foi a elaboração do zoneamento para fins ecoturísticos, do distrito de Rancharia, Município de Lima Duarte, MG, por ser uma opção de lazer próximo ao Parque Estadual da Serra do Ibitipoca. O zoneamento, integrante do processo de planejamento, visa à redução dos usos conflitivos do solo mediante o reconhecimento das zonas de recreação, a manutenção do uso estável de zonas críticas, o desenvolvimento das comunidades tradicionais e dos monumentos culturais que proporcionam oportunidades de caráter educativo, de pesquisa e monitoramento do ecoturismo. Entre os principais resultados alcançados, pode-se citar a confecção da planta semicadastral da comunidade de Rancharia, que foi a base de todo o ordenamento da atividade eco turística, a qual se encontra em estágio inicial de desenvolvimento. $\mathrm{O}$ zoneamento final resultou em quatro zonas adequadamente caracterizadas com base nos critérios previamente estabelecidos. A metodologia mostrou-se adequada para o planejamento da região, encontrando alto potencial para o desenvolvimento das atividades de ecoturismo em razão do estágio de preservação dos patrimônios natural e cultural.
\end{abstract}

Palavras-chave: Ecoturismo, planejamento, unidades de conservação; zoneamento e manejo.

\section{ZONING OF THE SURROUNDING AREA OF IBITIPOCA MOUNTAIN RANGE STATE PARK AIMING AT ECOTOURISM MANAGEMENT}

\begin{abstract}
The objective of this work was to draw up the zoning of the district of Rancharia, municipality of Lima Duarte, MG, for ecotourism purposes, using THE ECOPLANET INSTITUTE methodology (1994). Zoning, which is part of the planning process, seeks to reduce soil use conflict through the recognition of recreation zones, maintenance of stable use of critical zones, development of traditional communities and cultural monuments that provide opportunities for education, research and monitoring of ecotourism projects. Among the main accomplished results there is the making of the semi-cadastral map for the community of Rancharia, being used as the basis for the whole regulation of the ecotourism activity, which is presently at the initial stage of development. The final zoning resulted in four appropriately characterized zones based on previously established criteria. THE ECOPLANET INSTITUTE methodology was proven suitable for planning of the area, with a high potential for the development of ecotourism activities considering the preservation conditions of the natural and cultural patrimonies.
\end{abstract}

Keywords:Ecotourism, planning, units of conservation; zoning e management.

\footnotetext{
${ }^{1}$ Recebido em 04.05.2007 e aceito para publicação em 19.05.2008.

${ }^{2}$ Programa de Pós-Graduaçãoem Ciência Florestal da UniversidadeFederal de Viçosa(UFV), Viçosa-MG.E-mail:<wvmoraes@ hotmail.com>.

${ }_{3}^{3}$ Departamento de Engenharia Florestal da UFV. E-mail: < gribeiro@ ufv.br>.
} 


\section{INTRODUÇÃO}

A atividade de ecoturismo deve ser praticada de acordo com um padrão de desenvolvimento que possibilite o empresário e a comunidade local do meio rural gerenciar os empreendimentos, valendo-se de uma administração estratégica.

O ecoturismo e outros serviços desenvolvidos em áreas naturais apresentam diversos tipos de impacto ambiental sobre os recursos naturais. Estes recursos, como se encontram, necessitam de ordenamento, porque são o objeto das atividades ofertadas aos visitantes que acessam as porções de áreas naturais, como opção de recreação e lazer.

A administração estratégica é um processo contínuo e interativo, voltado para a manutenção de uma organização como um todo, integrado de forma apropriada a seu ambiente. O próprio processo envolve a realização de uma análise do ambiente, o estabelecimento de diretrizes organizacionais, a formulação da estratégia organizacional, a implementação organizacional e a aplicação do controle estratégico (CERTO, 1993).

De acordo com Curry (1987), o sucesso ou o fracasso do planejamento para o ecoturismo depende da análise de mercado, do planejamento, da participação local e da instrução dos financiadores. Esses fatores estão interligados e podem ser usados como uma ferramenta básica para o planejamento do ecoturismo, visando a otimização do local, o que é essencial para a estabilidade em longo prazo.

Os Parques Nacionais e outras unidades de conservação (UC) adotadas no Brasil como estratégia de conservação da biodiversidade, são áreas naturais protegidas que se constituem, atualmente, em uma das melhores oportunidades de desenvolvimento do ecoturismo, quando comparados às atividades clássicas de desenvolvimento (mineração, agricultura, manufatura de matéria-prima, estradas, hidrelétricas etc.) (MILANO, 1991). A parceria com a iniciativa privada para implantar serviços relativos ao ecoturismo e ao uso público é uma interessante forma de acelerar sua implementação e envolver a sociedade na questão, devendo ser vista como uma forma de melhorar a qualidade dos serviços, mas não como substituição do papel do poder público.

Lima et al. (2005) questionam o uso dos recursos públicos cada vez mais escassos, apregoando expectativas de ação e de conservação sem nenhuma programação de captação de recursos para gerenciamento da área ou para indenização dos proprietários.

Takahashi et al. (2005) complementam que a maioria dos administradores das unidades de conservação no Brasil não tem acesso á literatura estrangeira, disponível apenas em algumas bibliotecas especializadas.

Assim, alguns pontos de estrangulamento da atividade e visitação em UCs estão relacionados ao despreparo de muitos gerentes para a gestão das atividades de visitação, associado ao pequeno contingente de pessoal, aos poucos recursos financeiros e a planejamento, à existência de atrativos e à conscientização e capacitação da população do entorno. Para estas comunidades, as dificuldades estão relacionadas à sua pouca qualificação para atendimento das atividades ligadas ao turismo, aos poucos recursos financeiros e à falta de mobilização social.

Quando um sistema de planejamento começa a operar, o primeiro passo a ser dado é definir seu âmbito de ação em função do ambiente em que a atividade está inserida. Essa tarefa consiste em dividir o sistema de planejamento em partes, de acordo com uma série de critérios técnicos (CEBALLOS, 1999), a qual realizou uma série de oficinas de Capacitação em Ecoturismo no Brasil, cujo objetivo foi planejar o turismo ecológico de forma estratégica.

A metodologia proposta permite guiar futuras ações como prever problemas, antecipar cenários, sistematizar uma sequiência lógica de passos, avaliar continuamente as alternativas, ter a comunidade como base, interagir e dinamizar, integrar, abranger, multissetorizar, além de focalizar os recursos naturais e culturais. A referida metodologia, que foi a base do presente estudo, se baseia em:

- Afirmação da Missão e Estabelecimento de Objetivos - fornece o enfoque e a direção do planejamento do produto ecoturístico, demonstrando a visão geral de valores coerentes com as necessidades e projetos a serem implantados.

- Levantamento e Análise de Recursos - classifica a singularidade de cada recurso levantado em função de sua peculiaridade, possibilidade de atrair visitantes, acessibilidade, integridade e contribuição à proteção ambiental e cultural.

- Identificação de Impactos e Restrições - identifica os parâmetros que definirão os impactos negativos 
que poderão ser causados pelo ecoturismo em função dos limites de mudanças aceitáveis dentro de grupos populacionais que serão afetados pelo turismo.

- Pesquisa e Análise de Mercado - levanta informação inicial para desenvolver uma base de dados e para auxiliar na tomada de decisão, visando elaborar uma estratégia de marketing coerente com a realidade da comunidade.

- Conceituação Geral de Desenvolvimento - determina a orientação para o desenvolvimento global do ecoturismo e as oportunidades de produtos para a comunidade. O presente estudo teve como principal objetivo realizar o zoneamento ecoturístico do distrito de Rancharia, município de Lima Duarte, MG, por estar a região recebendo um fluxo alternativo de ecoturistas que sem uma sistematização da atividade poderá gerar vários impactos ambientais, sociais e financeiros, comprometendo a atividade.

\section{MATERIAL E MÉTODOS}

A área de estudo, onde foi aplicada a metodologia proposta pelo The Ecoplanet Institute (1994), compreende o distrito de Rancharia e sua comunidade rural, localizado no município de Lima Duarte, MG.

A comunidade de Rancharia apresentava á época, uma população de 59 habitantes adultos e 26 crianças. Situa-se geograficamente a $16 \mathrm{~km}$ do Parque Estadual de Ibitipoca e a $34 \mathrm{~km}$ da sede do município de Lima Duarte. O patrimônio local era composto de 18 casas da comunidade tradicional, 1 igreja católica, 1 campo de futebol, 2 estabelecimentos comerciais e 6 casas de turistas, com infra-estrutura básica de iluminação parcial e arruamento parcial. Na área rural, encontravamse 20 propriedades com área média de 20 ha. Conforme Tabela 1.

A atividade agrícola era representada basicamente pelo plantio de culturas de subsistência de lavoura branca como arroz, feijão e milho. O gado de leite era a fonte de renda principal das propriedades rurais, representada pelo leite e seus subprodutos, como o queijo. A fruticultura do caqui ocorre em pequenos pomares domésticos.

O Parque Estadual do Ibitipoca está inserido na Serra de Ibitipoca, uma vertente da Serra da Mantiqueira, com 1488 ha. Possui 4 áreas de camping com capacidade para 90 barracas, banheiros masculinos e femininos, quiosques e lanchonete, casa de pesquisadores e um centro de interpretação ambiental.

O zoneamento da área de estudo foi feito por meio do processo de compatibilização, de produtos e de mercados a partir da utilização dos dados gerados no levantamento e na análise dos vários recursos da comunidade, selecionando-se, de cada categoria, os mais significativos e de maior potencial para o desenvolvimento do ecoturismo.

O mapa da área foi elaborado a partir de dados de campo obtidos com o uso da Estação Total Elta 55, e processados pelo software Data Geosis, da Alezi Teodolini. O processamento incluiu o cálculo de coordenadas, a inserção de pontos, a geração de curvas de nível e a inserção dos lotes, construções, vias, hachuras e textos. $\mathrm{O}$ mapa em formato digital foi dividido em layers, para permitir a combinação dos temas de interesse.

A base cartográfica elaborada gerou a planta semicadastral da Comunidade de Rancharia, contendo a rede elétrica, malha viária, relevo, rios e córregos, e florestas, lotes e construções.

Após o levantamento das informações básicas, foram realizadas reuniões e visitas em locais pontuais para definição do uso do solo, visando a atividade de ecoturismo. As visitas foram realizadas com as lideranças da comunidade com o objetivo de levantar subsídios para elencar as áreas prioritárias do zoneamento.

O produto resultante do pré-zoneamento foi apresentado à comunidade para incorporar novas sugestões e adequar o zoneamento aos seus interesses.

\section{RESULTADOS}

De acordo com a metodologia, a área de estudo foi zoneada de acordo com as seguintes etapas:

A zona de serviços, identificada com base no mapa gerado, foi definida por meio de entrevistas com turistas e da aplicação de questionários com a Comunidade de Rancharia. Esta zona engloba todo o espaço a partir do ponto de chegada do turista até o ponto de partida para o local onde serão desenvolvidas as atividades.

R. Árvore, Viçosa-MG, v.32, n.4, p.751-758, 2008 


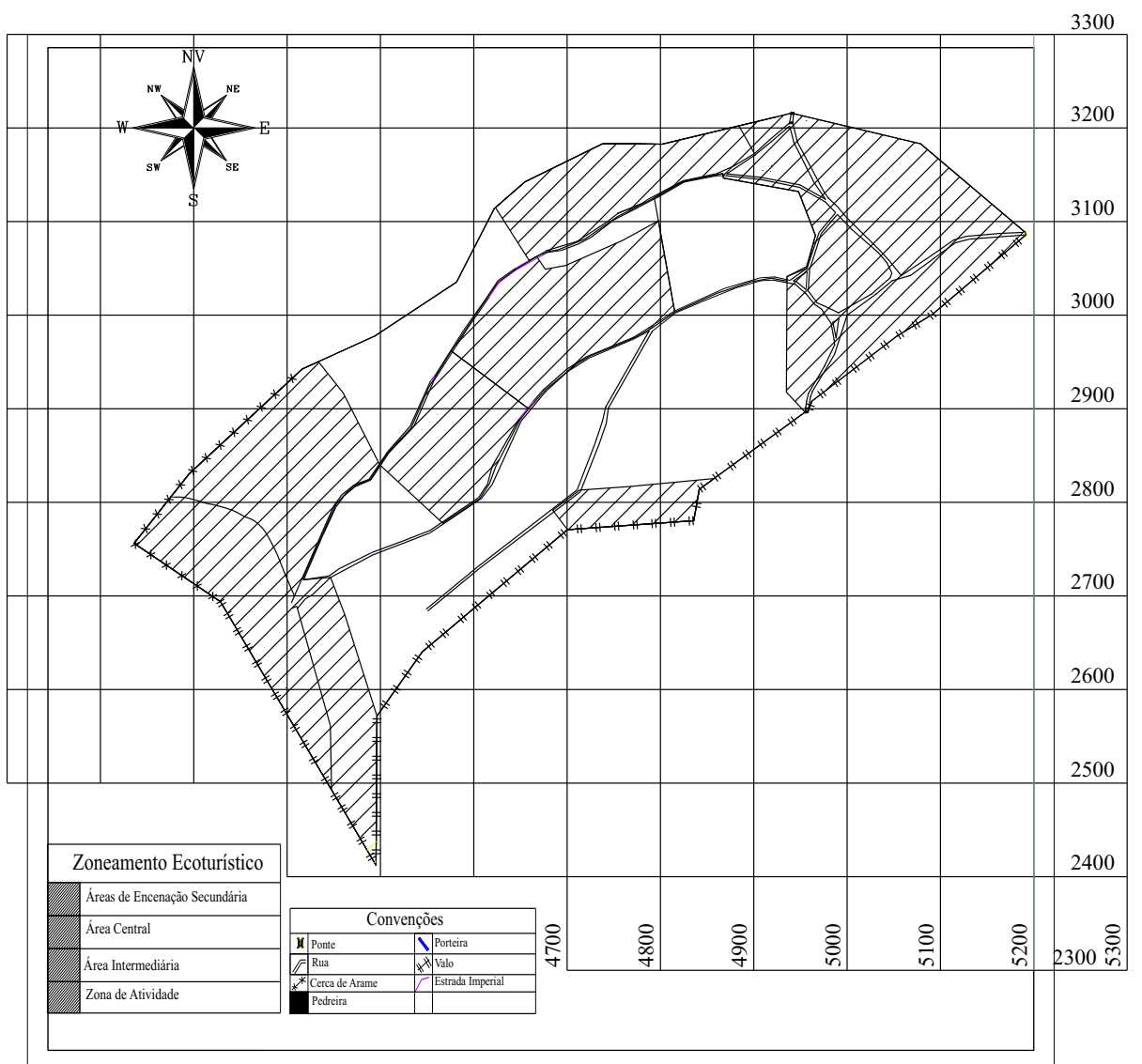

Figura 1 - Mapa do zoneamento ecoturístico da Comunidade de Rancharia, Município de Lima Duarte, MG. Figure 1 - Map of the ecotourism zoning of the Community of Rancharia, Municipality of Lima Duarte, MG.

Tabela 1 - Relação dos lotes da Comunidade de Rancharia, Município de Lima Duarte, MG Table 1 - List of plots of the Community of Rancharia, Municipality of Lima Duarte, MG

\begin{tabular}{|c|c|c|c|}
\hline $\mathrm{N}^{\mathrm{o}}$ do lote & Área $\left(\mathrm{m}^{2}\right)$ & $\mathrm{N}^{o}$ do lote & Área $\left(\mathrm{m}^{2}\right)$ \\
\hline 01 & 391,1632 & 20 & $13.679,22$ \\
\hline 02 & $1.029,4686$ & 21 & 992,83 \\
\hline $03,04,05$ & $2.499,4486$ & 22 & 649,04 \\
\hline 06 & 832,5123 & 23 & 583,91 \\
\hline 07 & $14.184,5261$ & 24 & 539,11 \\
\hline 08 & 565,9751 & 25 & 886,94 \\
\hline 09 & 162,9286 & 26 & 533,04 \\
\hline 10 & 146,0653 & 27 & $1.158,28$ \\
\hline 11 & $1.338,6666$ & 28 & 647,59 \\
\hline 12 & 296,5878 & 29 & $1.004,36$ \\
\hline 13 & $1.421,5658$ & 30 & $1.096,39$ \\
\hline 14 & $2.798,1449$ & 31 & $1.856,99$ \\
\hline 15 & 498,0176 & 32 & $1.674,56$ \\
\hline 16 & 626,0151 & 33 & 569,30 \\
\hline 17 & 505,4988 & Campo de futebol & $5.017,70$ \\
\hline 18 & 294,5295 & Cemitério & 232,45 \\
\hline 19 & $3.826,0038$ & Floresta & $64.746,23$ \\
\hline
\end{tabular}

R. Árvore, Viçosa-MG, v.32, n.4, p.751-758, 2008 
Os seguines aspectos foram considerados no inventário dessas áreas:

a) Acomodação - preferência por albergues, pousadas, pensões, chalés, etc. As instalações devem ser avaliadas por seu caráter arquitetônico e estético, localização, culinária nativa ou local, hospitalidade e preço.

b) Restaurante - locais que ofereçam um ambiente característico ou pitoresco, com ênfase na comida caseira.

c) Pontos de varejo - venda de material artístico, artesanato e disponibilidade ou venda de equipamentos para atividades de esporte ao ar livre.

d) Operadores locais - operadores de viagem receptivos incluindo serviços de guia, companhia de ônibus, operadores de aluguel, etc.

e) Transporte - identificação dos meios de transporte (ônibus, táxi, animais de carga, etc.), avaliados em termos da confiabilidade, qualidade, hospitalidade e o conhecimento da área por parte de quem os dirige.

f) Serviços públicos - levantamento dos serviços de segurança, tratamento de água, posto médico, correios, bancos e outros.

A zona central de ecoturismo está freqüentemente associada às áreas protegidas dentro da região de trabalho, as quais possuem seu próprio zoneamento. Alguns locais são vetados à visitação pública e devem ser preservados para a vida silvestre. As áreas primitivas podem estar conectadas por corredores ecológicos para garantir a segurança da vida selvagem e podem ter o acesso restrito a turistas ou podem ser criadas exclusivamente para garantir a qualidade ambiental na comunidade. A avaliação da zona central de ecoturismo foi feita por uma equipe multidisciplinar em 3 visitas técnicas e envolveu os seguintes aspectos:

a) Dimensão - tamanho da área protegida, uma vez que superfície maior é menos vulnerável ou sensível que uma área de pequena extensão.

b) Isolamento - nível de atividade humana/antrópica.

c) Densidade de paisagem - estado de conservação da diversidade biológica.

d) Grau de intervenção - tempo que a natureza levará para se recuperar. e) Forma -forma geométrica da área protegida, tendo em vista que ela influi na efetividade da proteção devido ao efeito de borda.

Conforme a figura 1 , a localização da referida zona se encontra em localização central no distrito e próxima á zona intermediária de ecoturismo, facilitando as atividades e o fluxo de ecoturistas em Rancharia.

A zona intermediária de ecoturismo a ser usada para experiências ecoturísticas, possibilita o acompanhamento dos ecoturistas por guias e intérpretes qualificados. A área foi inventariada por meio de questionários aplicados junto à comunidade e por entrevistas realizadas com turistas, atentando para a existência de produtos culturais, ambientais e convívio com a comunidade nativa. A análise baseou-se nos seguintes aspectos:

a) Recursos de eventos especiais - eventos de caráter local.

b) Centros Interpretativos - existência de local de informações turísticas.

c) Impactos Sócio-Culturais - identificação dos impactos negativos que podem ser causados pelo ecoturismo em cada grupo populacional.

d) Capacidade de suporte - seleção dos indicadores dos limites de mudança aceitáveis para posterior monitoramento do local visando o manejo da atividade de ecoturismo.

A referida zona, concebida para se desenvolver eventos e educação ambiental, se encontra em posição privilegiada no distrito, facilitando o seu manejo, conforme figura 2 .

A zona da atividade de ecoturismo proporciona aos ecoturistas e adeptos do turismo de aventuras uma série de atividades de acordo com as aptidões e potencialidades dos recursos naturais inventariados, como nome e tipo do recurso natural; oferta de uso atual e potencial no que se refere a oportunidades, acessibilidades, atividades atuais, atividades potenciais, facilidades, demanda e sazonalidade.

Conforme a Tabela 2, as atividades levantadas demonstram que valores agregados podem ser criados de forma a possibilitar uma interação entre as atividades, maximizando a experiência do ecoturista na região de Rancharia.

R. Árvore, Viçosa-MG, v.32, n.4, p.751-758, 2008 
Tabela 2 - Oportunidades de ecoturismo desenvolvidas na comunidade de Rancharia

Table 2-Ecotourism opportunities developed in the community of Rancharia

\begin{tabular}{|c|c|c|c|c|c|}
\hline Oportunidades & Acessibilidade & $\begin{array}{l}\text { Atividades } \\
\text { atuais }\end{array}$ & $\begin{array}{l}\text { Atividades } \\
\text { potenciais }\end{array}$ & Facilidades & Demanda \\
\hline Aventura & $\begin{array}{l}\text { Moderada a } \\
\text { difícil, a pé }\end{array}$ & Rapel & $\begin{array}{l}\text { Escalada } \\
\text { iluminação parcial, } \\
\text { estacionamento, bar }\end{array}$ & Mirante, trilha, & Jovens, casais \\
\hline Cultural & Fácil, a pé & Folia de Reis & $\begin{array}{l}\text { Encontro de folias; } \\
\text { Festival folclórico }\end{array}$ & $\begin{array}{l}02 \text { grupos de folia, } \\
\text { vestimenta e } \\
\text { instrumentos musicais }\end{array}$ & $\begin{array}{c}\text { População local, } \\
\text { melhor idade }\end{array}$ \\
\hline Ecoturismo & $\begin{array}{l}\text { Fácil a moderada } \\
\text { a cavalo }\end{array}$ & $\begin{array}{l}\text { Cavalgadas na } \\
\text { comunidade } \\
\text { fotografia }\end{array}$ & $\begin{array}{l}\text { Roteiros longos } \\
\text { pelas propriedades } \\
\text { rurais }\end{array}$ & $\begin{array}{l}\text { Animais bem } \\
\text { tratados }\end{array}$ & Todos os turistas \\
\hline
\end{tabular}

O mapa do zoneamento ecoturístico (Figura 1) foi gerado a partir da relação dos lotes (Tabela 1) existentes no distrito de Rancharia e suas respectivas áreas, compondo a planta semicadastral da área de estudo.

Esses dados foram a base para montar a proposta de zoneamento de Rancharia e para o ordenamento da atividade de ecoturismo a ser implantada.

O planejamento das zonas descritas na metodologia foram assim caracterizadas:

a) Zona de serviços: Por se tratar de uma área que não irá, a princípio, receber ecoturistas para pernoite, dado o grau de hierarquia frente ao Distrito de Conceição de Ibitipoca, onde existe estrutura para acomodações, essa área foi definida como sendo o primeiro contato entre o ecoturista e a comunidade, ocorrendo, assim, a recepção aos visitantes. Essa zona fornecerá serviços como entretenimento e recreação, alimentação, guias, roteiros personalizados, aluguéis de equipamentos e transporte e venda de artesanatos. Nessa área encontram-se, atualmente, todas as estruturas de Rancharia, como iluminação, bares, campo de futebol e, pela sua localização, é o portal de entrada da comunidade. Foi identificado um único local que serve de alimentação, do tipo comida caseira.

Pontos de varejo são inexistentes, mas a comunidade disponibiliza, em feriados, várias barracas para venda de artesanato e alimentação com quitutes doces e salgados.

Por iniciativa própria, alguns guias anunciam, por meio de cartazes rústicos, seus serviços e passeios a cavalo, os quais têm boa receptividade. Alguns estão vinculados as operadoras de ecoturismo de Ibitipoca e até mesmo da capital mineira.

O transporte de turistas até Rancharia é feito por dois táxis e um ônibus escolar da Prefeitura Municipal de Lima Duarte, embora nos feriados apenas os táxis operam. Para passeios no local utilizam-se cavalos de aluguel.

A comunidade de Rancharia ainda não dispõe de nenhum serviço público, exceto iluminação. A comunicação é garantida por um único telefone público. Já foram feitas reivindicações solicitando água tratada, posto de saúde, rede de esgotos e antena de celular.

Um programa de manejo do meio ambiente para fins ecoturísticos tem a finalidade de subsidiar o controle do fluxo ecoturístico de forma a ordenar e direcionar a visitação para áreas que apresentem condições ambientais e sociais para uma experiência de visita enriquecedora (FERREIRA, 1997). Neste sentido, a zona de serviços cumprirá o seu objetivo de manter as características naturais e culturais da área, não comprometendo as futuras gerações.

b) Zona central de ecoturismo: Sua situação geográfica na comunidade se justifica por estar entre as áreas de encenação, onde ocorre um fluxo intenso de visitantes e a área intermediária de ecoturismo. A topografia acidentada e o tipo de solo existente são um fator limitante para a construção de edificações que contrastam com as da comunidade. 
As restrições de uso de uma área central de ecoturismo são um requisito essencial para se buscar a sustentabilidade de um produto, pois expressará a imagem do tipo de experiência que está sendo oferecido (MCKERCHER, 2002).

Nesta área serão implementadas estruturas que não tragam nenhuma movimentação de terra e que venham acompanhar a topografia da região, dando condições à fauna e a flora de permanecerem sustentando ecologicamente a comunidade. As estruturas residenciais existentes e que venham a existir deverão receber diretrizes de uso do solo para minimizar os impactos ambientais.

Com base nos parâmetros de dimensão, isolamento, densidade da paisagem, grau de intervenção e forma geométrica, foram encontradas e classificadas as seguintes áreas: com características de horto botânico (6); com ênfase em plantas medicinais (4); áreas para jardins botânicos (4); e áreas para implantação de Reserva Particular do Patrimônio Natural - RPPN (2), todos em terras privadas.

c) Zona Intermediária de Ecoturismo: esta zona foi eleita junto com a comunidade para a implantação dos seguintes eventos: festival de folclore, festival de música de raiz e festival gastronômico e a construção de um centro interpretativo para visitantes e exposição permanente da região.

Com relação á capacidade de suporte, o limite de mudança aceitável na área ambiental foi identificado a partir da presença de lixos na área de estudo; para o limite de mudança aceitável de infra-estrutura foi identificada a degradação do patrimônio arquitetônico; para o limite de mudança aceitável psicológico foi identificada a diminuição das reuniões comunitárias quando são realizados os encontros da comunidade. Segundo Catie (1992), a definição de capacidade de suporte não é uma solução por si mesma, é uma ferramenta de manejo que se apóia e sustenta decisões, é um parâmetro dinâmico, tem que considerar os limites aceitáveis de uso além de considerar as variáveis limitantes. Assim, se justifica a determinação dos limites de mudanças como um indicativo que possibilita acompanhar a dinâmica das atividades ecoturísticas que serão desenvolvidas em rancharia.

Neste sentido, estes indicativos de impacto ambiental deverão ser monitorados para que não seja ultrapassado o limite que desestruture a vida social, econômica e ambiental da comunidade. d) Zona de atividade de ecoturismo: As oportunidades mostradas no Tabela 2 foram identificadas a partir da iniciativa da comunidade em planejar o ecoturismo.

Miller (1980) cita que o zoneamento físico para o manejo da atividade ecoturística contribui para evitar usos conflitivos do solo, reconhecer áreas onde se pode estabelecer recreação e lazer, assegurando o uso estável de zonas críticas para o desenvolvimento das comunidades tradicionais. Assim, se estabeleceu as oportunidades de ecoturismo para a comunidade de Rancharia.

\section{CONCLUSÕES}

Com base nos dados levantados e nas análises realizadas, pode-se concluir que:

- A metodologia mostrou-se adequada para o planejamento da atividade ecoturística na área estudada, por abranger os aspectos naturais, sociais e de sustentabilidade da atividade.

- O zoneamento proposto definiu quatro categorias de zonas, adequadamente caracterizadas, possibilitando o desenvolvimento da atividade ecoturística de forma planejada por se encontrar em seu estágio inicial de desenvolvimento.

- O distrito de Rancharia possui um alto potencial para o desenvolvimento das atividades de ecoturismo em função do estágio de preservação dos seus patrimônios natural e cultural.

- O ecoturismo em Rancharia apresenta baixo fluxo de visitantes, principalmente pela pouca estrutura para atendimento aos mesmos.

- O local é utilizado como uma oportunidade de relaxamento pelos ecoturistas que visitam o Parque Estadual de Ibitipoca e que não encontram lá o sossego desejado.

\section{R. REFERÊNCIAS}

CATIE. Apostila do XIV Curso Internacional de Áreas protegidas, 02 a 27 de março de 1992, Turrialba - Costa Rica. Centro Agronômico de Treinamento e Investigação e Estudos. 1992.

CERTO, S C., PETER J. P. Administração estratégica: planejamento e implantação de estratégia. São Paulo. Makron Books. 1993.

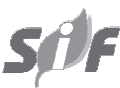

R. Árvore, Viçosa-MG, v.32, n.4, p.751-758, 2008 
CURRY, N. Recreation cost-benefit analysis and this equit effect. Journal of Environment Management, n. 25, p. 363-375, 1987.

CEBALLOS-LASCURÁIN, H. O ecoturismo como um fenômeno mundial. In: LINDBERG. K. HAWKINS, D. E. (Eds.). Ecoturismo: um guia para planejamento e gestão. 2. ed. São Paulo: SENAC, 1999. p.23-29.

FERREIRA, L.F. Oficinas de capacitação em ecoturismo. In: WORLD ECOTOUR'97, 12, 1997, Rio de Janeiro. Anais..., n.1, v. 1, p. 1168-171. Biosfera, 1997.

GUMERCINDO, S. L., GUIDO, A. R., ANTONIO. G. W. Avaliação da efetividade de manejo das unidades de conservação de proteção integral em Minas Gerais. Revista Árvore, Viçosa, v. 29, n. 4, p. 647-653, 2005.
LEIDE Y. T., MIGUEL S. M., CÁSSIO A. T. Indicadores de impacto para monitorar o uso público no Parque Estadual Pico do Marumbi - Paraná. Revista Árvore. Viçosa, v. 29, n. 1, p.159-167, 2005.

MILANO, M. S. Curso básico de gestão ambiental. Módulo: instrumento de gestão ambiental - Estratégia de conservação da biodiversidade. IBAMA, ENAP, PNMA, 1991. 77p.

MCKERCHER, B. Turismo de natureza: planejamento e sustentabilidade. São Paulo: Contexto, 2002. 302p.

MILLER, K. Planificacion de parques nacionales para el ecodesarrollo em latinoamerica. FEPMA - Fundación para la Ecologia y la proteccion del Medio Ambiente. 1980. 500p.

THE ECOPLANNET INSTITUTE. Oficinas de capacitação em ecoturismo. Fazenda Intervales. São Paulo, 1994. 